\title{
Video Article \\ Generation of Human Induced Pluripotent Stem Cells from Peripheral Blood Using the STEMCCA Lentiviral Vector
}

\author{
Andreia Gianotti Sommer ${ }^{1}$, Sarah S. Rozelle ${ }^{1}$, Spencer Sullivan ${ }^{2}$, Jason A. Mills ${ }^{3}$, Seon-Mi Park ${ }^{1}$, Brenden W. Smith ${ }^{1}$, Amulya M. Iyer ${ }^{1}$, Deborah \\ L. French ${ }^{3}$, Darrell N. Kotton ${ }^{1}$, Paul Gadue ${ }^{3}$, George J. Murphy ${ }^{1}$, Gustavo Mostoslavsky ${ }^{1}$ \\ ${ }^{1}$ Center for Regenerative Medicine (CReM), Boston University School of Medicine \\ ${ }^{2}$ Department of Hematology, Children's Hospital of Philadelphia \\ ${ }^{3}$ Center for Cellular and Molecular Therapeutics, Children's Hospital of Philadelphia
}

Correspondence to: Gustavo Mostoslavsky at gmostosl@bu.edu

URL: http://www.jove.com/video/4327/

DOI: $10.3791 / 4327$

Keywords: Stem Cell Biology, Issue 68, Induced pluripotent stem cells (iPSCs), peripheral blood mononuclear cells (PBMCs), reprogramming, single excisable lentiviral vector, STEMCCA

Date Published: 10/31/2012

Citation: Sommer, A.G., Rozelle, S.S., Sullivan, S., Mills, J.A., Park, S., Smith, B.W., Iyer, A.M., French, D.L., Kotton, D.N., Gadue, P., Murphy, G.J., Mostoslavsky, G. Generation of Human Induced Pluripotent Stem Cells from Peripheral Blood Using the STEMCCA Lentiviral Vector. J. Vis. Exp. (68), e4327 10.3791/4327, DOI : 10.3791/4327 (2012).

\section{Abstract}

Through the ectopic expression of four transcription factors, Oct4, Klf4, Sox2 and cMyc, human somatic cells can be converted to a pluripotent state, generating so-called induced pluripotent stem cells (iPSCs) ${ }^{1-4}$. Patient-specific iPSCs lack the ethical concerns that surround embryonic stem cells (ESCs) and would bypass possible immune rejection. Thus, iPSCs have attracted considerable attention for disease modeling studies, the screening of pharmacological compounds, and regenerative therapies ${ }^{5}$.

We have shown the generation of transgene-free human iPSCs from patients with different lung diseases using a single excisable polycistronic lentiviral Stem Cell Cassette (STEMCCA) encoding the Yamanaka factors ${ }^{6}$. These iPSC lines were generated from skin fibroblasts, the most common cell type used for reprogramming. Normally, obtaining fibroblasts requires a skin punch biopsy followed by expansion of the cells in culture for a few passages. Importantly, a number of groups have reported the reprogramming of human peripheral blood cells into iPSCs ${ }^{7-9}$. In one study, a Tet inducible version of the STEMCCA vector was employed ${ }^{9}$, which required the blood cells to be simultaneously infected with a constitutively active lentivirus encoding the reverse tetracycline transactivator. In contrast to fibroblasts, peripheral blood cells can be collected via minimally invasive procedures, greatly reducing the discomfort and distress of the patient. A simple and effective protocol for reprogramming blood cells using a constitutive single excisable vector may accelerate the application of iPSC technology by making it accessible to a broader research community. Furthermore, reprogramming of peripheral blood cells allows for the generation of iPSCs from individuals in which skin biopsies should be avoided (i.e. aberrant scarring) or due to pre-existing disease conditions preventing access to punch biopsies.

Here we demonstrate a protocol for the generation of human iPSCs from peripheral blood mononuclear cells (PBMCs) using a single floxedexcisable lentiviral vector constitutively expressing the 4 factors. Freshly collected or thawed PBMCs are expanded for 9 days as described ${ }^{10,11}$ in medium containing ascorbic acid, SCF, IGF-1, IL-3 and EPO before being transduced with the STEMCCA lentivirus. Cells are then plated onto MEFs and ESC-like colonies can be visualized two weeks after infection. Finally, selected clones are expanded and tested for the expression of the pluripotency markers SSEA-4, Tra-1-60 and Tra-1-81. This protocol is simple, robust and highly consistent, providing a reliable methodology for the generation of human iPSCs from readily accessible $4 \mathrm{ml}$ of blood.

\section{Video Link}

The video component of this article can be found at http://www.jove.com/video/4327/

Protocol

\section{Isolation and Expansion of Peripheral Blood Mononuclear Cells (PBMCs)}

\section{DAY 0}

1. Draw $4 \mathrm{ml}$ of peripheral blood into a BD Vacutainer CPT Cell Preparation Tube with sodium citrate. Invert the tube 8 to 10 times and centrifuge at $1,800 \times \mathrm{g}$ for $30 \mathrm{~min}$ at room temperature. Ideally, this step should be done within $2 \mathrm{hr}$ of collection.

2. Collect the mononuclear cells (MCs) by pipetting the buffy coat (cell layer between gel barrier and plasma) into a sterile $15 \mathrm{ml}$ conical centrifuge tube. Bring total volume to $10 \mathrm{ml}$ with sterile phosphate-buffered saline (PBS), invert several times and centrifuge at $300 \mathrm{xg}$ for 15 $\min$. 
3. Resuspend the cells in $10 \mathrm{ml}$ of sterile PBS and perform cell count. Transfer 1 to $2 \times 10^{6}$ cells into a sterile $15 \mathrm{ml}$ conical centrifuge tube and centrifuge at $300 \mathrm{xg}$ for $10 \mathrm{~min}$.

4. Resuspend the cells in $2 \mathrm{ml}$ of expansion medium (EM) (QBSF-60 Stem Cell Medium containing $50 \mu \mathrm{g} / \mathrm{ml}$ Ascorbic Acid, $50 \mathrm{ng} / \mathrm{ml} \mathrm{SCF}, 10$ $\mathrm{ng} / \mathrm{ml} \mathrm{IL-3,} 2 \mathrm{U} / \mathrm{ml}$ EPO, $40 \mathrm{ng} / \mathrm{ml}$ IGF-1, $1 \mu \mathrm{M}$ Dexamethasone and $100 \mu \mathrm{g} / \mathrm{ml}$ primocin or $1 \%$ Pen/Strep) and transfer to one well of a 12-well plate. Incubate the cells in a $37^{\circ} \mathrm{C}, 5 \% \mathrm{CO}_{2}$ incubator.

5. Centrifuge remaining cells at $300 \times \mathrm{g}$ for $10 \mathrm{~min}$ and freeze $\sim 2 \times 10^{6}$ cells/vial in FBS containing $10 \%$ DMSO.

6. To start the protocol using frozen PBMCs, thaw 1 vial of cells into $10 \mathrm{ml}$ of QBSF medium and centrifuge at $300 \times \mathrm{g}$ for $10 \mathrm{~min}$. Resuspend the cells in $2 \mathrm{ml}$ of EM and transfer to one well of a 12-well plate. Incubate the cells in a $37{ }^{\circ} \mathrm{C}, 5 \% \mathrm{CO}_{2}$ incubator.

\section{DAY 3 and DAY 6}

17. Transfer the cells to a sterile $15 \mathrm{ml}$ conical tube and wash the well once with $1 \mathrm{ml}$ of QBSF-60 Stem Cell Medium to collect adherent cells.

18. Centrifuge the cells at $300 \mathrm{xg}$ for $10 \mathrm{~min}$.

19. Resuspend the cells in $2 \mathrm{ml}$ of EM and transfer to one well of a 12 -well plate. Incubate the cells in a $37{ }^{\circ} \mathrm{C}, 5 \% \mathrm{CO}_{2}$ incubator.

\section{Transduction of PBMCs with STEMCCA Lentivirus}

\section{DAY 9}

1. Transfer the cells to a sterile $15 \mathrm{ml}$ conical tube and wash the well once with $1 \mathrm{ml}$ of QBSF-60 Stem Cell Medium to collect adherent cells.

2. Centrifuge the cells at $300 \times \mathrm{g}$ for $10 \mathrm{~min}$.

3. Resuspend the cells in $1 \mathrm{ml}$ of fresh EM containing $5 \mu \mathrm{g} / \mathrm{ml}$ of polybrene and STEMCCA lentivirus (MOI=1 to 10 ) and transfer to one well of a 12-well plate. (The protocol describing production of lentiviral particles can be found at http://www.bumc.bu.edu/stemcells/protocols/)

4. Spin the plate at $2,250 \mathrm{rpm}$ at $25^{\circ} \mathrm{C}$ for $90 \mathrm{~min}$.

5. After spin, add an additional $1 \mathrm{ml}$ of fresh EM containing $5 \mu \mathrm{g} / \mathrm{ml}$ of polybrene for a total of $2 \mathrm{ml}$ of medium and incubate the plate in a $37{ }^{\circ} \mathrm{C}$, $5 \% \mathrm{CO}_{2}$ incubator.

\section{DAY 10}

16. Transfer the cells to a sterile $15 \mathrm{ml}$ conical tube and wash the well once with $1 \mathrm{ml}$ of QBSF-60 Stem Cell Medium to collect adherent cells. 17. Centrifuge the cells at $300 \mathrm{xg}$ for $10 \mathrm{~min}$.

18. Resuspend the cells in $2 \mathrm{ml}$ of EM and transfer to 1 well of a 12 -well plate. Incubate the cells in a $37^{\circ} \mathrm{C}, 5 \% \mathrm{CO}_{2}$ incubator.

\section{Plating Transduced Cells onto MEFs}

\section{DAY 11}

1. Coat the wells of a 6 -well plate with $0.1 \%$ gelatin and plate inactivated mouse embryonic fibroblasts (MEFs) at $2 \times 10^{5}$ cells $/$ well in MEF medium (IMDM containing 10\% FBS, $1 \%$ Non-Essential Amino Acids, $100 \mu \mathrm{M} \beta$-mercaptoethanol, $2 \mathrm{mM} \mathrm{L-Glutamine,} 100 \mu \mathrm{g} / \mathrm{ml}$ primocin or $1 \%$ Pen/Strep). Prepare 3 wells per infection.

\section{DAY 12}

2. Transfer the cells to a sterile $15 \mathrm{ml}$ conical tube and wash the well once with $1 \mathrm{ml}$ of QBSF-60 Stem Cell Medium to collect adherent cells.

3. Resuspend the cells in $3 \mathrm{ml}$ of MEF medium containing $10 \mathrm{ng} / \mathrm{ml} \mathrm{bFGF}$, and Ascorbic Acid and growth factors at the same concentrations as used in EM medium ( $50 \mu \mathrm{g} / \mathrm{ml}$ Ascorbic Acid, $50 \mathrm{ng} / \mathrm{ml} \mathrm{SCF}, 10 \mathrm{ng} / \mathrm{ml}$ IL-3, $2 \mathrm{U} / \mathrm{ml} \mathrm{EPO}, 40 \mathrm{ng} / \mathrm{ml}$ IGF-1, $1 \mu$ M Dexamethasone).

4. Plate $1 \mathrm{ml}$ of cells per well of a 6-well plate containing MEFs. Add $1.5 \mathrm{ml}$ of MEF media with bFGF, Ascorbic Acid, and growth factors for a total of $2.5 \mathrm{ml}$ of media/well.

5. Spin the plate at $500 \mathrm{rpm}$ at $25^{\circ} \mathrm{C}$ for $30 \mathrm{~min}$. Incubate the plate in a $37^{\circ} \mathrm{C}, 5 \% \mathrm{CO}_{2}$ incubator.

\section{DAY 14}

6. Feed cells every other day with $2.5 \mathrm{ml}$ of MEF media containing $10 \mathrm{ng} / \mathrm{ml} \mathrm{bFGF}$ and $50 \mu \mathrm{g} / \mathrm{ml}$ Ascorbic Acid (no growth factors). Aspirate and discard floating cells with each feed.

7. Add additional MEFs as needed (usually once a week).

\section{DAY 20}

8. Once small colonies appear, feed cells daily with $2 \mathrm{ml}$ of human embryonic stem cell (hESC) medium (DMEM/F12 containing $20 \%$ Knockout Serum Replacement, 1\% Non-Essential Amino Acids, $100 \mu \mathrm{M} \beta$-mercaptoethanol, $2 \mathrm{mM}$ L-Glutamine, $100 \mu \mathrm{g} / \mathrm{ml}$ primocin or $1 \%$ Pen/Strep and $10 \mathrm{ng} / \mathrm{ml} \mathrm{bFGF).}$

\section{Picking and Expansion of iPSC Clones}

\footnotetext{
$\sim$ DAY $30-40$
}

1. Pick each colony in individual wells of a 12-well plate pre-seeded with inactivated MEFs containing $1 \mathrm{ml} /$ well of hESC medium plus $10 \mu \mathrm{M}$ of Stemolecule Y27632 (ROCK inhibitor). 
2. Feed cells daily thereafter with $1 \mathrm{ml}$ of hESC medium only (no ROCK inhibitor).

\section{Immunofluorescence Staining for Pluripotency Markers}

1. Staining was performed using the kit "ES Cell Marker Sample Kit" from Millipore and following the manufacturer's protocol.

\section{Excision of Integrated STEMCCA Vector}

1. Excision of reprogramming cassette is achieved utilizing a Cre-IRES-Puro expressing vector following transfection and brief Puromycin selection as described ${ }^{6}$.

\section{Representative Results}

We demonstrate a simple and effective protocol for the generation of human iPSCs from PBMCs using a single lentiviral vector. Figure 1A shows a schematic representation of the protocol. The blood is collected into a BD Vacutainer CPT Cell Preparation Tube with sodium citrate, and after centrifugation, mononuclear cells can be collected from the interface between the polyester gel and the plasma (buffy coat) (Figure 1B). The isolated PBMCs are then expanded in culture for 9 days. Figure 2 compares PBMCs at day 0 and day 9 , showing that the cells are noticeably dividing. Approximately 10-15 days post-transduction with the STEMCCA lentivirus, appearance of small bright colonies are observed, with still undefined colony morphology. Following the addition of hESC medium, hESC-like colonies can be easily identified (Figure 2D). Some of these colonies are mechanically picked, expanded and characterized for the expression of pluripotency markers such as SSEA-4, Tra-1-60 and Tra-1-81 (Figure 3). Using a brief Puromycin selection approach ${ }^{6}$, we are able to consistently obtain transgene-free iPSC clones as depicted in Figure 4.

A

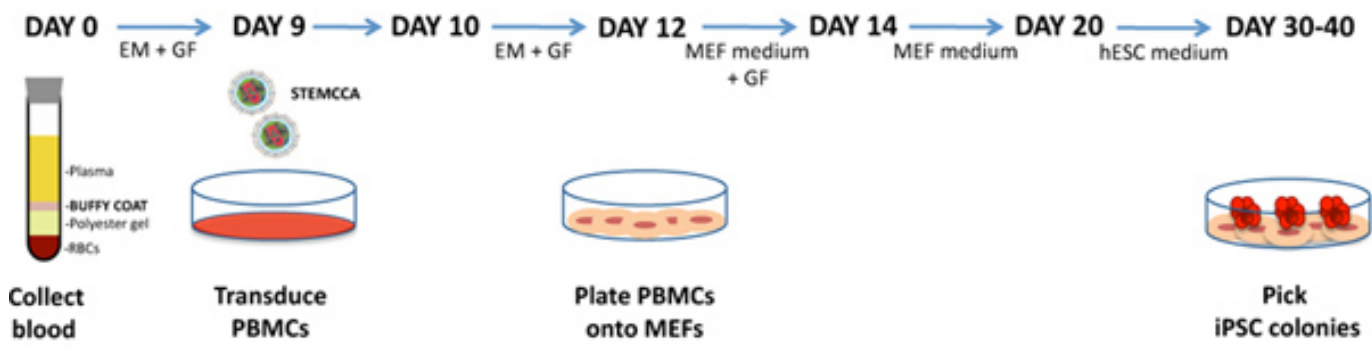

B

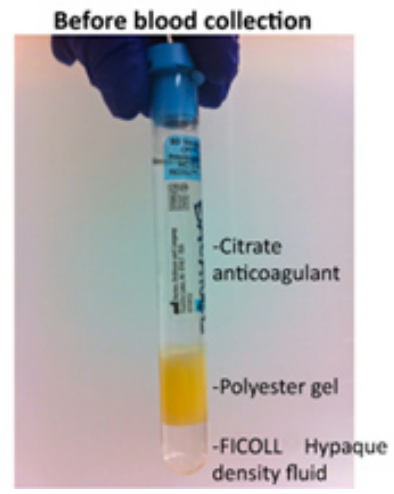

Before centrifugation

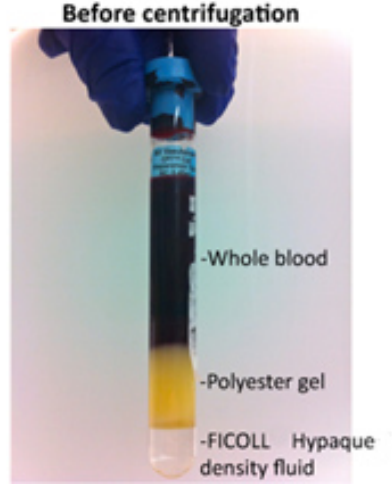

After centrifugation

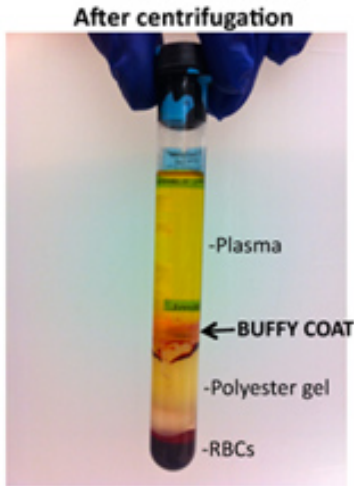

Figure 1. Generation of human iPSCs from peripheral blood. A) Schematic representation of the protocol used to generate human iPSCs from peripheral blood mononuclear cells (PBMCs) using the STEMCCA vector. EM: Expansion Medium; GF: Growth Factors; RBC: Red Blood Cells; MEF: Mouse Embryonic Fibroblast; hESC: human Embryonic Stem Cell. B) BD Vacutainer CPT Cell Preparation Tube with sodium citrate used for the collection of whole blood and the separation of mononuclear cells. The separation occurs during centrifugation when the gel barrier separates the mononuclear cells and plasma from the denser blood components. After centrifugation, mononuclear cells and platelets can be isolated from a whitish layer (buffy coat) just under the plasma layer. Click here to view larger figure. 

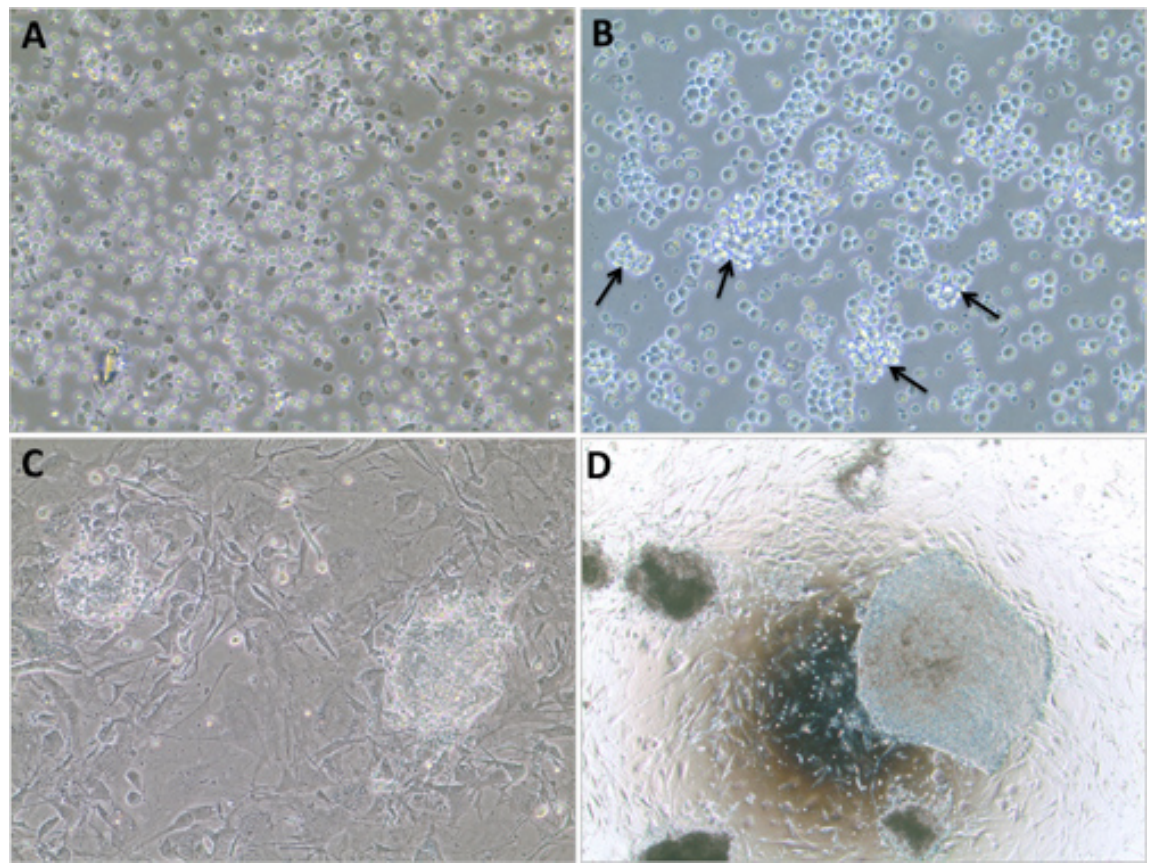

Figure 2. Representative images of morphological changes of the cells throughout the protocol. A) DAY 0: mononuclear cells are isolated from peripheral blood and cultured in expansion medium. 20x magnification. B) DAY 9: after expansion in culture for 9 days, 'bunch of grapes-like' clusters of cells are observed (arrows) suggesting that the cells are healthy and proliferating before being transduced. 20x magnification. C) DAY 20: colony formation is observed one week after the cells are plated onto MEFs. 10x magnification. D) DAY 30: hESC-like iPSC colonies show typical morphology and are ready for picking and expansion. 4x magnification.
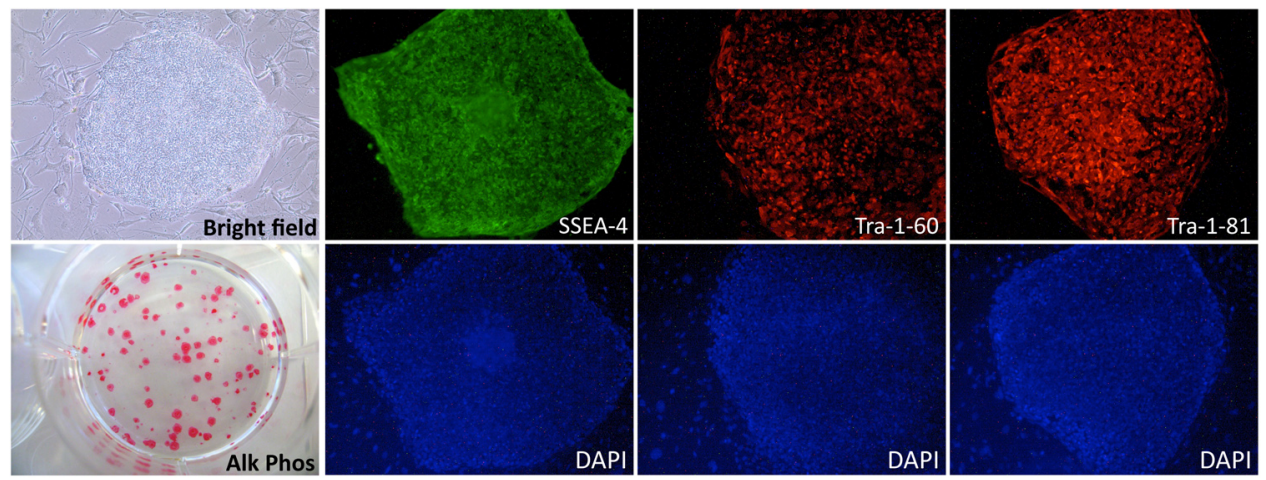

Figure 3. Characterization of human iPSCs generated from blood. Immunofluorescence analysis of iPSCs generated from PBMCs showing the expression of the pluripotency markers SSEA-4, Tra-1-60 and Tra-1-81. The iPSCs also stain positive for Alkaline Phosphatase (Alk Phos).

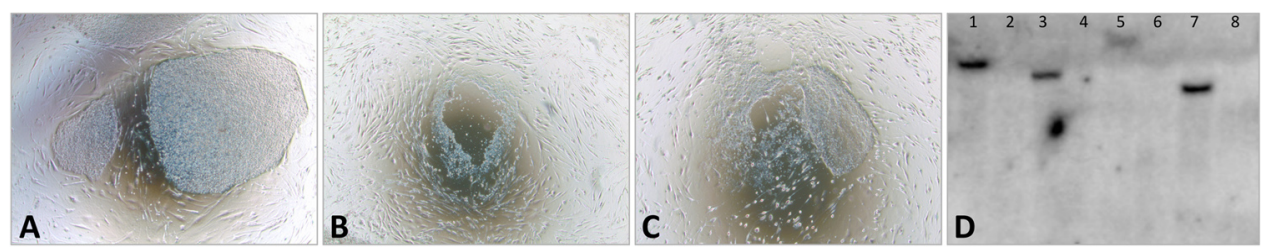

Figure 4. Generation of transgene-free iPSCs. iPSCs are transfected with a plasmid coexpressing Cre recombinase and a puromycinresistance gene, as described in Somers et al, 2010. A) iPSCs before transfection. B) Cell death is observed after two days of puromycin selection C) New colonies emerge from resistant cells around 10 days after transfection. D) Some colonies are picked and expanded, and Southern Blot is performed to confirm the excision of the transgene. 1, 3, 5 and 7: iPSC clones before excision; 2, 4, 6 and 8: iPSC clones after excision. All phase contrast images at $4 x$ magnification. 


\section{Discussion}

We herein describe the use of the STEMCCA lentiviral vector to generate human iPSCs from mononuclear cells isolated from a few milliliters of freshly collected peripheral blood. The protocol can also be used to reprogram frozen PBMCs (obtained directly from the buffy coat), a detail of significant practical implications when utilizing donor cells acquired from a distant location. Before the induction of reprogramming, isolated PBMCs must undergo a critical expansion step that renders a healthy proliferating population of cells more amenable to nuclear reprogramming. This is easily observed by the presence of 'bunch of grapes-like' clusters of cells upon expansion in hematopoietic culture conditions. When less than $5 \times 10^{5}$ cells are transduced, cells may be plated onto one or two wells of a 6-well plate containing MEFs. We have experienced some variability in the time necessary to observe hESC-like colonies, in some cases up to 25 days post-transduction. The use of ROCK inhibitor is critical to enhance the survival and cloning efficiency upon picking of emerging iPSC colonies. Remarkably and in contrast to what we observed when picking colonies from reprogrammed fibroblasts, virtually $100 \%$ of picked colonies from reprogrammed PBMCs establish stable iPSC clones that can be expanded and cryopreserved. Finally, we believe that the simplicity of the sample collection combined with the highly efficient and consistent reprogramming approach described herein, represent a bona fide platform for applications in which large numbers of iPSC clones need to be generated.

\section{Disclosures}

No conflicts of interest declared.

\section{Acknowledgements}

These studies were funded in part by NIH UO1HL107443-01 Award to GJM and GM.

\section{References}

1. Lowry, W.E., Richter, L., Yachechko, R., et al. Generation of human induced pluripotent stem cells from dermal fibroblasts. Proc. Natl. Acad. Sci. U.S.A. 105, 2883-2888 (2008).

2. Park, I.H., Zhao, R., West, J.A., et al. Reprogramming of human somatic cells to pluripotency with defined factors. Nature. 451, 141-146 (2008).

3. Takahashi, K., Tanabe, K., Ohnuki, M., et al. Induction of pluripotent stem cells from adult human fibroblasts by defined factors. Cell. 131, 861-872 (2007).

4. Yu, J., Vodyanik, M.A., Smuga-Otto, K., et al. Induced pluripotent stem cell lines derived from human somatic cells. Science. 318, 1917-1920 (2007).

5. Stadtfeld, M. \& Hochedlinger, K. Induced pluripotency: history, mechanisms, and applications. Genes Dev. 24, 2239-2263 (2010).

6. Somers, A., Jean, J.C., Sommer, C.A., et al. Generation of transgene-free lung disease-specific human induced pluripotent stem cells using a single excisable lentiviral stem cell cassette. Stem Cells. 28, 1728-1740 (2010).

7. Loh, Y.H., Hartung, O., Li, H., et al. Reprogramming of T cells from human peripheral blood. Cell Stem Cell. 7, 15-19 (2010).

8. Seki, T., Yuasa, S., Oda, M., et al. Generation of induced pluripotent stem cells from human terminally differentiated circulating T cells. Cell Stem Cell. 7, 11-14 (2010).

9. Staerk, J., Dawlaty, M.M., Gao, Q., et al. Reprogramming of human peripheral blood cells to induced pluripotent stem cells. Cell Stem Cell. 7, 20-24 (2010).

10. Chou, B.K., Mali, P., Huang, X., et al. Efficient human iPS cell derivation by a non-integrating plasmid from blood cells with unique epigenetic and gene expression signatures. Cell Res. 21, 518-529 (2011).

11. van den Akker, E., Satchwell, T.J., Pellegrin, S., Daniels, G., \& Toye, A.M. The majority of the in vitro erythroid expansion potential resides in CD34(-) cells, outweighing the contribution of CD34(+) cells and significantly increasing the erythroblast yield from peripheral blood samples. Haematologica. 95, 1594-1598 (2010). 